\title{
Hyaline droplet formation in the renal epithelium of patients with haemoglobinuria
}

\author{
S. J. BRYANT
}

From the Department of Pathology, Royal Brisbane Hospital, Brisbane, Queensland, Australia

SYNOPSIS Renal hyaline droplet formation is described in two patients with haemoglobinuria. The droplets were shown to contain haemoglobin by a histochemical method. The findings are correlated with the results of recent experimental studies which have demonstrated that renal hyaline droplets are phagosomes containing absorbed protein and not products of cellular degeneration as was previously thought.

The nature and significance of hyaline droplets in renal tubular cells has been the subject of much debate and conjecture. Until recently they were considered to be a manifestation of cell degeneration (Allen, 1962). It is now clear that they are vacuoles containing protein absorbed from the tubule lumen (Straus, 1957a and b; Miller, 1960; Ericsson, 1964, 1965). Biochemical and histochemical studies have shown that they are related to lysosomes (Straus, 1957a and b; Ericsson, 1964, 1965). Haemoglobin has been used as a marker protein to study their formation and fate in experimental animals at the level of electron microscopy (Miller, 1960; Ericsson, 1964, 1965).

Hyaline droplets in human renal epithelium are frequently seen in disease, but it has proved difficult to demonstrate that they do in fact contain reabsorbed protein. Haemoglobin in tissues can be detected by a histochemical method (Pearse, 1960). In the present report, haemoglobin-containing hyaline droplets are described in the renal epithelium of two patients who died of Clostridium perfringens septicaemia with haemoglobinuria.

\section{CLINICAL FEATURES AND MACROSCOPIC NECROPSY FINDINGS}

CASE 1 A 74-year-old diabetic male was admitted to the Royal Brisbane Hospital complaining of severe retrosternal chest pain of six hours' duration. An electrocardiograph revealed a left bundle branch block not present on previous examinations. A diagnosis of acute myocardial infarction was made. During the next 24 hours the patient became hypotensive and intramuscular injections of metaraminol (Aramine) were given into the right thigh in an attempt to maintain an adequate blood

Received for publication 7 March 1967. pressure. Metaraminol was subsequently administered as an intravenous infusion. On the third day, the right thigh became swollen and it was soon obvious that there was gas gangrene of the lateral thigh muscles. At opera- $\vec{\bullet}$ tion, the necrotic muscles were widely excised. Clostrid- 9 ium perfringens was cultured from the skin and surgically excised muscle. The patient died soon after completion of the operation.

Necropsy was performed 17 hours after death. There was subcutaneous gas extending from the right axilla to below the right knee. The remainder of the lateral $\stackrel{\perp}{\perp}$ thigh muscles were necrotic, and this necrosis and gas $\underset{F}{\Rightarrow}$ formation extended to involve the right psoas major $ᄋ$ muscle and adjacent retroperitoneal tissues. The blood was grossly haemolysed and the arterial endothelium was stained red. There was a dissecting aneurysm of the descending thoracic aorta. Macroscopically the kidneys appeared quite congested. The haemoglobin concentration in the supernatant of centrifuged urine was $0 \cdot 8 \mathrm{~g} . / 1$.

CASE 2 A 35-year-old woman was admitted to the Royal Brisbane Hospital complaining of lower abdomi- 을 nal pain and blood loss per vaginum of 12 hours' dura- $D$ tion. She was thought to be suffering from a ruptured o tubal pregnancy. Her serum was noted to be very dark indicating haemolysis, and her urine contained large $\mathcal{N}$ amounts of methaemoglobin. Laparotomy revealed a N parametritis and septic abortion. Gram-positive rods $N$ were seen on a smear, and Clostridium perfringens was $\omega$ cultured from the cervical discharge. Despite vigorous treatment death occurred eight hours after admission. 6 At necropsy the findings at laparotomy were confirmed. Macroscopically the kidneys appeared congested.

\section{HISTOLOGICAL AND HISTOCHEMICAL} EXAMINATIONS OF THE KIDNEYS

Blocks of renal tissue were fixed in $10 \%$ formol saline $\stackrel{\mathbb{Q}}{\complement}$ and blocked in paraffin. Four micron sections were cut. 


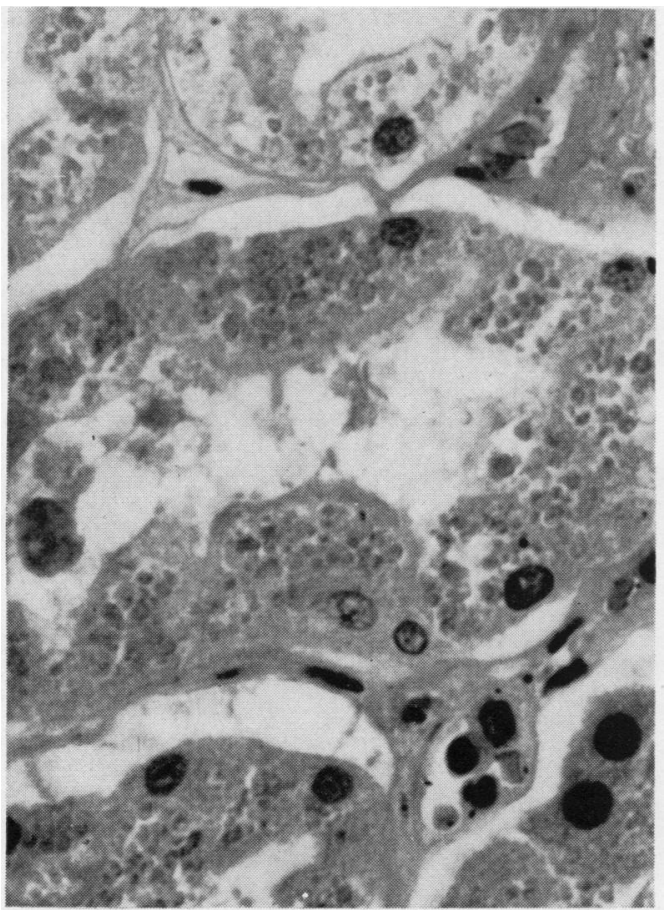

FIG. 1

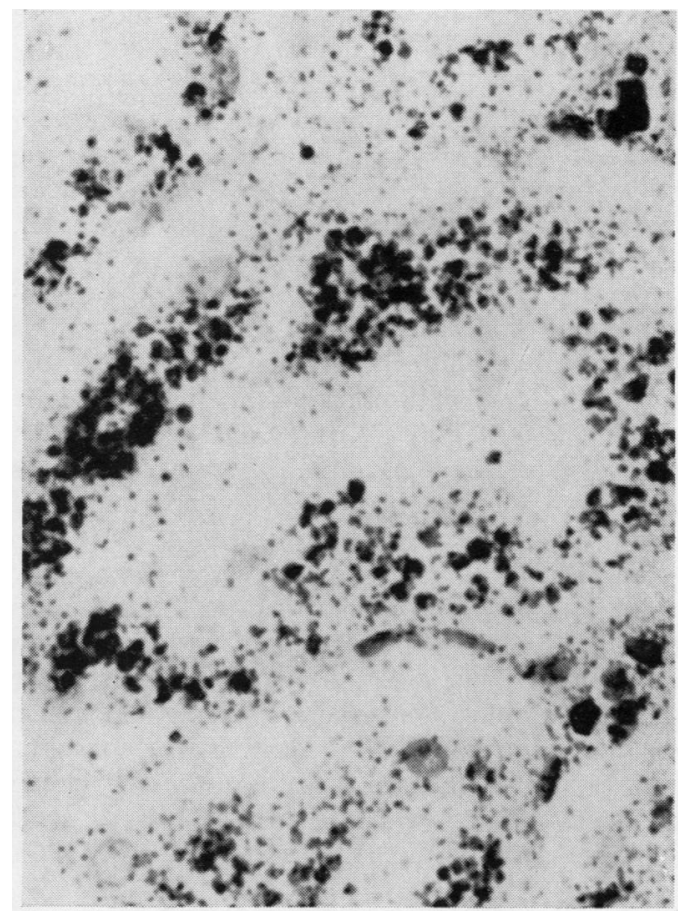

FIG. 2

FIG. 1. Renal proximal tubules in transverse section. There are numerous hyaline droplets of varying size in the cytoplasm of epithelial cells. Haematoxylin and eosin. $\times 750$.

FIG. 2. Corresponding area of section immediately adjacent to that illustrated in Figure 1. Cytoplasmic granules similar to those seen in Figure 1 stain intensely for haemoglobin. Erythrocytes in two capillaries have also stained. Tiny granules are due to tissue peroxidases. Benzidine stain for haemoglobin. $\times 750$.

Alternate sections were stained with haematoxylin and eosin and with benzidine for haemoglobin (Pearse, 1960). Sections were also stained for iron by Perls' method (Pearse, 1960). It is to be noted that the benzidine reaction is not specific for haemoglobin but rather for the haem molecule (Pearse, 1960). Whether the stained absorption droplets contain myoglobin (in case 1) or breakdown products of haemoglobin (in both cases) instead of haemoglobin, in no way invalidates the interpretation of the results.

The histology of the kidneys from both cases was similar, the changes being more advanced in case 1 . In the haematoxylin-and-eosin-stained sections, there was extensive hyaline droplet formation in the cells of many proximal tubules (Fig. 1). Hyaline granular material was present in Bowman's space and in the lumina of the convoluted tubules and collecting tubules. In sections stained with benzidine, this material gave a positive reaction for haemoglobin (Fig. 2). By studying adjacent sections it can be seen that the hyaline and haemoglobin droplets are one and the same (Figs. 1 and 2). There was no stainable iron in the proximal convoluted tubular cells. There were no degenerative changes in renal proximal tubular cells.

\section{DISCUSSION}

For many years, hyaline droplets in renal proximal tubular cells were regarded as evidence of cellular degeneration. The droplets were considered to be accumulations of damaged cellular proteins and indeed many standard textbooks still put forward this view (Allen, 1962). Smetana (1947) described labelled proteins being filtered through glomeruli and resorbed by renal proximal tubular cells. Rather (1948) injected haemoglobin into the peritoneal cavities of rats and found that the haemoglobin content of the renal proximal tubular cells increased to a maximum at 17 hours after injection. The iron content of the cells reached a maximum at 65 hours after injection. Oliver, MacDowell, and Lee (1954) came to the conclusion that the absorption droplets 
were associated with mitochondria, if they were not, in fact, swollen mitochondria. In 1957 Strauss found that absorption droplets isolated from rat kidney homogenates contained both marker protein and digestive enzymes which indicated that the droplets were similar to the subcellular particles described by de Duve (1959) and called lysosomes. Miller (1960), in an electron microscopic study, described absorption vacuoles containing haemoglobin which appeared to arise from invaginations of the cell membrane of epithelial cells near the bases of the microvilli. This was corroborated by Ericsson, Mostofi, and Weibel (1963) who described the absorption droplets which streamed towards cytoplasmic areas rich in Golgi apparatus and lysosomes. The absorption droplets appeared to fuse with preexisting lysosomes or, by some other method, to acquire lysosome-like properties. Ferritin was later found in these structures, indicating a breakdown of haemoglobin. Similar results were obtained by Strauss (1964a and b) using horseradish peroxidase as the marker protein. These concepts, as well as a more detailed account of the absorption and digestion of protein by proximal tubular cells, are illuminated by the studies of Ericsson (1964, 1965).

There is now little doubt that hyaline droplets in renal proximal tubular cells are absorption droplets (phagosomes) and they subsequently acquire lysosomal properties, thereby becoming phagolysosomes. The two examples described demonstrate the relationship between hyaline droplets and haemoglobin absorption droplets, a relationship infrequently noted in human tissue but well documented in laboratory animals.

I am grateful to Dr. A. Davison of the Institute of Forensic Pathology, Brisbane, who provided renal tissue from case 2, and Mr. B. Stewart for the photographs.

\section{REFERENCES}

Allen, A. C. (1962). The Kidney. Medical and Surgical Diseases, 2nd ed., p. 330. Churchill, London.

de Duve, C. (1959), In Subcellular Particles, edited by T. Hayashi, p. 128. Ronald Press, New York.

Ericsson, J. L. E. (1964). Acta path. microbiol. scand., suppl. 168.

-, (1965). Lab. Invest., 14, 1.

—, Mostofi, F. K., and Weibel, J. (1963). Ibid., 12, 853.

Miller, F. (1960). J. biophys. biochem. Cytol., 8, 689.

Oliver, J., MacDowell, M., and Lee, Y. C. (1954). J. exp. Med., 99, 589.

Pearse, A. G. E. (1960). Histochemistry; Theoretical and Applied, 2nd. ed., pp. 652, 928, 931, Little, Brown, Boston. Churchill, London.

Rather, L. J. (1948). J. exp. Med., 87, 163.

Smetana, H. (1947). Amer. J. Path., 23, 255.

Straus, W. (1957a). J. biophys. biochem. Cytol., 3, 933.

(1957b). lbid., 3, 1037.

_ (1964a). J. Cell Biol., 20, 497.

(1964b). Ibid., 21, 295. 